\title{
A Critical Review: Language Learning Strategy and Teachers' Characteristics in Indonesian English Language Teaching
}

\author{
Emilda Oktaviyani \\ University of Lampung, Indonesia \\ (emildaoktaviyani@gmail.com)
}

\begin{abstract}
This paper discusses the relation between language learning strategy (LLS) and teachers' characteristics. The objective of this study is to investigate the effect of teachers' characteristics in students' language learning strategy that will lead to the success of students in mastering English. The study was conducted by giving the teachers' characteristics and LLS queationnaires to 50 secondary level students. This study employed descriptive qualitative method. The finding showed a positive correlation between teachers' characteristics and students' language learning strategy. Teachers' characteristics strongly affect the way students learn. Once the students feel comfortable to the class and the teachers, it is just a piece of cake to master the lesson. In sum, as English teachers, it is better to mind our characteristics.
\end{abstract}

Keywords: Teachers' Characteristics, Students' Language Learning Strategy (LLS) and EFL

In Indonesian context of English Language Teaching (ELT), English is taught as a foreign language (EFL). In addition, English is a compulsary subject for secondary school. Unfortunately, despite studying English for six years in junior and senior high school, many of Indonesian students still exhibit low proficiency in English up-on graduation from senior high school (Imperianti, 2012; Lie, 2007; Mercellino, 2008; Larson, 2014). This is attributed to many factors including: large class size, low English proficiency of teachers, low salary, not enough teacher education to teach the new curriculum, and cultural barriers hindering teachers from adopting a facilitator role in English as EFL class (Dardjowidjojo, 2000; Nur, 2004; Larson, 2014). Highlighing the two obstacles, large class size and teachers' problem, in this case, the former deals with students' learning strategy (LLS) and the latter with teachers' characteristics. This issue becomes the main concern of this study.

LLS is creativity or action of learners to accomplish their learning goals. Rubun (1981: 42) defines LLS as 'the techniques or devices that a learner may use to acquire language'. A further definition, Oxford (1990) defines LLS as specific method/technique employed by individual learners to facilitate their comprehension, retention, retrieval, and application of information in second or foreign language. LLS, in the early reseach conducted by Rubin (1981) is defined as strategies that contribute directly and indirectly to second or foreign language learning. Six direct strategies include clarification/verification; (2) monitoring; (3) memorization; (4) guessing/inductive 
inference; (5) deductive reasoning; and (6) practice. Two direct strategies are: (1) creating opportunites; and (2) production tricks.

In addition, a different way of defining LLS as proposed by O'Malley and Chamot (1990), is that LLS includes cognitive, metacognitive and social/affective strategies. Cognitive strategy is used by learner to work with information to improve learning; metacognitive strategy is higher order exclusive skills that involve planning, monitoring or evaluating a language learning activity; and, social/affective strategy involves interaction with others or exert control over effect. A further classification is propossed by Oxford (1990) that is known as the Strategy Inventory for Language Learning (SILL). The definitions are as follows: (1) cognitive strategy deals with the processing information and structuring it, for example, analyzing, summarizing; (2) memory strategy deals with remembering information by making connections, for example, grouping and using keywords; (3) metacognitive strategy deals with meaning the learning process and dealing with the task, for example, planning, identifying and selecting resources; (4) compensation strategy deals with compensating for knowledge gaps, for example, guessing, gesturing; (5) affective strategy deals with identifying one's affective traits and knowledge of how to manage them, for example, reducing anxiety, encouraging one's self; and (6) social strategy deals with learning form and/or with others, for example, asking for corporation, working with peers.

Some studies conducted in LLS by Mistar and Umamah (2014) carried out the influence of gender on the strategy preferences and to measure the contribution of learning strategies to speaking proficiency. A study conducted by Hamdan and Matarima (2011) investigated the relation between students' motivation and LLS. Yet, it is needed to conduct more studies that relate to the way teachers teach and on how they understand each student's LLS. The way teachers teach relate to the teachers' characteristics.

Teachers' characteristics deal with the teachers' way of teaching. In this case, Hayati (2010) suggests that pedagogy is an approach to education that rooted in the experiences of marginalized people; that is centered in a critique of structural, economic, and racial operation; that is focused on dialogue instead on a one way transmission of knowledge; and that is transferred to empower individual and collectives as agents for social change.

In addition, based on Wallerstein (1983) outlines some basic steps for teachers' critical pedagogy which are first the instructor listens to the learners and identifies their problems. Then the instructuror listens to the learners and identifies their problems. Then the instructor provides codes based on the problems identified by the students should 'name the problem, understand how it applies on them, determine the causes of the problem, generalize to others, and finally, suggest alternatives or solutions to the problem. In sum, these steps involve the learners' activeness.

In Indonesia context, teachers' characteristics review is more about tachers' role in handling the classroom. In this case, the way teachers teach often neglect the students' activeness and they practice teacher-centered teaching in the classroom. This problem actually becomes the core problem in Indonesia. As stated by Azra (2002), a teachercentered class instruction is deeply embedded in Indonesian school settings, this sype of instruction has become a part of Indonesian school culture. In addition, teachers lack of pedagogy competence. Thus, it neglects the students' LLS. In 
addition, a study by Larson (2014) proposed that teachers' characteristics play important role in Indonesia EFL context.

Further classification related to teachers' characteristics are identified by Pettis (1997) that there are three main characteristics for a professionally competent teacher. According to her, an effective teacher must firstly be principled and knowledgeable in addition to being skillful. Secondly, professional needs and interests of an effective language teacher must change over time and develop during his/her teaching. Thirdly, a teacher must be personally committed to his/her professional development. Moreover, Borg (2006) argued that language teachers inducted learners into ways of thinking and being which reflect those of the target culture.

In terms of content, language teaching was regarded to be more complex and varied than other subjects. In terms of methodology, in the aforementioned study, the methods, activities and material used by or available to English language teachers were reported to be different from those in the other subjects. It was also found that English language teaching methodology was more progressive than that of other subjects, and consequently, English language teachers needed to be more up-to-date to cope with advanced and progressive nature of language teaching methodology. English language teachers were also supposed to have closer, more relaxed, and generally more positive relationships with learners in comparison to other teachers. One further source of distinction between English language teachers and teachers of other fields was that the former's language proficiency and command of the language was usually compared to that of native speakers of the target language (Borg, 2006). However, it is not clearly stated if this final point is a merit or a demerit for language teachers.

Good characteristics of language teachers have been described in the literature as having not only a profound competence in the target language but a set of personal qualities like sensitivity, warmth and tolerance (Vadillio, 1999). In an investigation of the characteristics of good language teachers, Brosh (1996) found the desirable characteristics of an effective language teacher to be: having knowledge and command of the target language; being able to organize, explain, and clarify, as well as to arouse and sustain interest and motivation among students; being fair to students by showing neither favoritism nor prejudice; and being available to students. Both language teachers and learners counted command of the target language and teaching comprehensibility as the most important characteristics to be possessed by an effective foreign language teacher. Moreover, the teachers gave more weight to items related to developing motivation and research orientation, whereas the students counted items related to treating students fairly and making lessons interesting more important as compared with the teachers' ideas on these very issues.

Reviewing the previous studies conducted in students' LLS and teachers' characteristics, the studies are done seperately. In this case, both LLS and teachers' characteristics should be related to each other. Thus, this study investigated the critical review on students' LLS and teachers' characteristics in Indonesian EFL context. 


\section{Method}

\section{Participants}

Participants of this study were secondary English language learners. They were 50 junior high school learners.

\section{Instrument}

A paper and pencil questionnaire comprising two sections (14 items and 6 open-ended questions) was developed by the researchers after a thorough review of the literature about qualities of an ELT. The questionnaire was developed in English and Indonesian and both versions were revised 4 times with the help of students and peers before being used in a pilot study to investigate how different items functioned and to find out whether there was a need to revise, add or drop any items. With comments received after pilot testing, two items were added to each section. The final version of the questionnaire which was administered along with a covering letter was made up of two sections. The first part of the questionnaire includes 14 statements about the characteristics of ELT and the relation with LLS and the participants were asked to express their agreement or disagreement based on whether the item is implemented or not. The second part consists of 6 open-ended questions to be answered by the participants.

\section{Data collection and procedure}

The researcher conducted the study in Junior High School 2 of Bandar Lampung. In addition, to gain the teachers' perspective towards the effectiveness of English language teacher, the researcher conducted the study in the English Language association in Lampung.

The questionnaire was distributed. All students were asked to fill the questionnaire and being interviewed by the researcher.

\section{Data analysis}

The responses to the correlation between teachers' characteristics and students' language learning are analyzed using SPSS. The responses to openended questions were analyzed mainly qualitatively.

\section{Result and Discussion}

The result of this study showed a possitive correlation between the teachers' characteristics and students' language learning strategies. The better teachers' characteristics are, the better students' language learning strategies are. The statistical data for this correlation is presented in Table 1 .

Table 1. Correlation Between Teachers' Characteristics and Students' Language Learning Strategy

\begin{tabular}{llrr} 
& & $\begin{array}{l}\text { Teachers' } \\
\text { characteristics }\end{array}$ & $\begin{array}{l}\text { Students' } \\
\text { Language } \\
\text { Learning } \\
\text { Strategy }\end{array}$ \\
\hline Teachers' characteristics & Pearson Correlation & 1 &, $359 * *$ \\
& Sig. (2-tailed) &, &, 000 \\
& N & 20 & 20 \\
\hline
\end{tabular}




\begin{tabular}{llrr}
\hline Students' Language Learning & Pearson Correlation &, $359 * *$ & 1 \\
Strategy & Sig. (2-tailed) &, 000 & 20 \\
& N & 20 \\
** Correlation is signficant at the 0.6 level (2-tailed). & &
\end{tabular}

Teacher plays an important role in the classroom. Good and qualified teachers are important for efficient educational function systems and for enhancing the quality of learning. The research supports this statement that a good teacher and actions to be taken on his part in the classroom play a vital role in provoking effective and efficient learning on the part of the students (Markley, 2004). Teachers also have a fundamental role in their learners' academic achievement and their quality can highly influence student outcomes (Campbell, Kyriakides, Muijsc \& Robinsona, 2004; Lasley II, Siedentop \& Yinger, 2006; Rockoff, 2004).

Based on the findings, learners of English hold some views towards some characteristics of an English language teacher. As Pettis (1997) notes, professionally competent English teachers are profoundly knowledgeable in language, and in line with the findings of Park and Lee (2006), Brosh (1996), and Kalabic (2005) most of the teachers in this investigation perceived knowledge of language a crucial factor in characterizing an effective English language teacher. This also confirms the findings of Calabria (1960), Feldman (1976) and Feldman (1988) who had founded mastery of subject matter as a characteristic of an effective teacher. Supporting these findings, teachers' characteristics not only give possitive effect to the students' English language mastery, but also give a positive effect towards students' language learning strategy (LLS). Similar to findings of Brosh (1996), one of the most striking points in the learners' responses was their emphasis on teacher's personality trait. Good tecahers' characteristics will lead the students to maximize their learning startegies.

\section{Conclusion}

The discussion in the preceding section leads us to the conclusion that emphasize on the teacher and target language knowledge. Teachers should invest more on education programs in order to improve their English proficiency so they can contribute to the process of training effective teachers. As the main source of language available to students, teachers' richer knowledge of and better proficiency in the language can help students to overcome their difficulties in communicative skills and maximize their learning strategies, too. Moreover, attending to students' needs will not only mean that teachers should seek to meet the learners' needs with regards to personality (whereby more attention must be paid to educational psychology), it will also mean that teachers will need to offer individualized instruction as far as possible in an attempt to cater for idiosyncratic learning styles of different learners. This latter concern will be taken care more effectively if the teachers are willing to take the learners' level into account and try to use the right techniques and procedures at the right proficiency level to suit their learners the best, all of which will materialize only when the teachers make themselves committed enough to 
their teaching duties by rigorously preparing themselves for the battlefield.

This study is by no means comprehensive and there are some limitations which may be addressed in future studies. The data were collected at one point in time in Indonesia, and as the nature of research in social settings entails, the views of English learners towards the characteristics of an English language teachers characteristics and their language learning strategies could change over time. The findings are therefore open for confirmation by replicating the research using more indepth qualitative analyses.

\section{References}

Azra, A. (2002). Paradigma Baru Pendidikan: Rekonstruksi dan Emokrasi. Jakarta: Kompas.

Djarwididjojo,S. (2000). English Teaching in Indonesia. EA Journal, $18(1), 23-30$.

Hamdan, Karin., \& Hmadan, R.A. (2011). Learners' Motivation and Learning Startegies in English Foreign Language (EFL) in Indonesian context. Journal of Edupers, I, 100 - 108.

Hayati, N. (2014). Empowering nonnative English Speaking Teaching Through Critical Pedagogy. TEFLIN Journal, 21(1), 78-89.

Imperianti,E. (2012). English Language Teaching in Indonesia and its relation to the role of english as an international language. Passage, J(1), 1-12.
Larson, Kasey R. (2004). Critical Pedagogie(ies) for EFL in Indonesia. TEFLIN Journal, 25(1), 122 - 138.

Lie, A. (2007). Education policy and EFL curriculum in Indonesia: Between the commitment to competence and the queat for higher test scores. TEFLIN Journal, 18(1), 1- 14.

Marcellino, M. (2008). English language teaching in indonesia: A continues challenge in education and cultural diversity. TEFLIN Journal, 19(1): 57-69.

Mistar, Junaidi \& Umamah, Atik (2014). Strategies of learning speaking skill by proficiency. TEFLIN Journal, 25(2), $203-216$.

O'malley,J.M., \& Chamot,A.U.(1990). Learning strategies in second language acquisition. Cambridge: Cambridge University Press.

Oxford, R.L.(1996). Language Learning Strategies around the world: Crosscultural perspectives. Honolulu: Univesity of Hawaii Press.

Rubin, J. (1981). Study of cognitive processes in second language learning. Applied Linguistics, 2, $117-131$.

Wellerstein,N. (1983). Language in culture in conflict: Problem - poising in the ESL classroom. Reading,M.A: Addison-Wesley Publishing Company. 